\title{
Engaging Families as True Partners During Hospitalization
}

\author{
Alisa Khan, MD, MPH', Sharon Cray, BBA², Alexandra N. Mercer, BA', \\ Matthew W. Ramotar, BA ${ }^{1}$, Christopher P. Landrigan, MD, MPH ${ }^{1,3}$
}

'Boston Children's Hospital, Boston, Massachusetts; ${ }^{2}$ St. Christopher's Hospital for Children, Philadelphia, Pennsylvania; ${ }^{3}$ Department of Medicine, Brigham and Women's Hospital, Boston, Massachusetts.

ommunication failures are a leading cause of sentinel events, the most serious adverse events that occur in hospitals. ${ }^{1}$ Interventions to improve patient safety have focused on communication between healthcare providers. ${ }^{2-4}$ Interventions focusing on communication between providers and families or other patient caregivers are under-studied.5,6 Given their availability, proximity, historical knowledge, and motivation for a good outcome, ${ }^{7}$ families can play a vital role as "vigilant partners" 8 in promoting hospital communication and safety.

In this month's Journal of Hospital Medicine, Solan et al. conducted focus groups and interviews of 61 caregivers of hospitalized pediatric patients at 30 days after discharge to assess their perceptions of communication during hospitalization and discharge home. ${ }^{9}$ They identified several caregiver themes pertaining to communication between the inpatient medical team and families, communication challenges due to the teaching hospital environment, and communication between providers. Caregiver concerns included feeling out of the loop, excessive provider use of medical jargon, confusing messages on rounds, and inadequate communication between inpatient and outpatient providers.

The manuscript serves both to uncover family concerns that may be underappreciated by clinicians and suggest some potential solutions. For instance, caregivers can be apprehensive about whom to call for postdischarge advice because they are sometimes uncertain whether their outpatient providers have sufficient information about the hospitalization to properly advise them. The authors propose using photo "face sheets" to improve caregiver identification of healthcare provider roles, including families in hospital committees, improving transition communication between inpatient and outpatient healthcare providers through timely faxed discharge summaries and telephone calls, and informing families about such communications with their outpatient providers.

These are important suggestions. However, in order to move from promoting communication alone to promoting true part-

*Address for correspondence: Alisa Khan, MD, MPH, Boston Children's Hospital, 21 Autumn St., Rm 200.2, Boston, MA 02215;

Telephone: 617-355-2565; Fax: 617-730-0957; E-mail: alisa.khan@childrens. harvard.edu

Received: October 6, 2017; Accepted: October 15, 2017

Published online first January 18, 2018.

2018 Society of Hospital Medicine DOI 10.12788/jhm.2920 nership in care, there are additional steps that providers can take to fully engage families in hospital and discharge communications.

Meaningful family engagement in hospital communications - eg, during family-centered rounds (FCRs) — has been associated with improved patient safety and experience. ${ }^{10-12}$ To further enhance family partnership in care, we would make the following 3 suggestions for hospitals and healthcare providers: (1) focus on health literacy in all communications with families, (2) work towards shared decision making (SDM), and (3) make discharges family-centered.

\section{HEALTH LITERACY}

In order to partner with one another, families and healthcare providers need to speak a common language. A key way to ensure that families and providers speak a common language is for providers to espouse good health literacy principles. Health literacy is the "capacity to obtain, process, and understand basic health information and services to make appropriate health decisions." 13 Health literacy is dynamic, varying based on medical problem, provider, and healthcare system. ${ }^{14}$ Overall, only $12 \%$ of United States adults possess the health literacy skills required to navigate our complex healthcare system. ${ }^{15,16}$ Stress, illness, and other factors can compromise the ability of even these individuals to process and utilize health information. Yet health literacy is routinely overestimated by providers. ${ }^{17-19}$

To optimize communication with families, providers should use "universal health literacy precautions"16 with all patients, not just those believed to need extra assistance, in both verbal (eg, FCRs) and written communications (eg, discharge instructions). ${ }^{16}$ Providers should speak in plain, nonmedical language, be specific and concrete, and have families engage in "teach-back" (ie, state in their own words their understanding of the plan). They should focus on what families "need to know" rather than what is "good to know." They should use simpler sentence structure and "chunk and check" 20 (ie, provide small, "bite-sized" pieces of information and check for understanding by using teachback). ${ }^{21}$ In writing, they should use simpler sentence structure, bullet points, active statements, and be cognizant of reading level, medical jargon, and word choice (eg, "has a fever" instead of "febrile"). It is worth recognizing that even highly educated, highly literate families - not least of all those who are physicians and nurses themselves - can benefit from universal health literacy precautions because the ability to process and grasp information is dynamic and can be markedly lower than usual when faced with the illness of a loved one. 
At a systematic level, medical schools, nursing schools, residency training programs, and continuing education should include health literacy training in their curricula. While learning to speak the language of medicine is an important part of medical education, the next step is learning to "unspeak" it, a challenging but important charge to promote partnership.

\section{SHARED DECISION MAKING}

SDM is the process by which providers and patients make decisions together by balancing clinical evidence with patient preferences and values. ${ }^{22}$ However, despite providers believing they are engaging in $\mathrm{SDM}_{1}^{23,24}$ families report they are often not as involved in SDM as they would like. ${ }^{24-26}$ Indeed, most hospital communications with families, including FCRs and discharge instructions, typically emphasize information sharing, not SDM. SDM tends to be more commonly applied in outpatient settings. ${ }^{27}$ To encourage SDM in the hospital setting, patients and families should not only understand communication during FCRs and at discharge but should be encouraged to be active participants in developing care plans, ${ }^{26}$ no matter how minor the decisions involved. ${ }^{28}$ SDM can be applied to a variety of discussions, both during hospitalization (eg, initiation of antibiotics, transition from intravenous to oral medications, pursuing imaging) and at discharge (eg, assessing discharge readiness, deciding duration of therapy, formulating follow-up recommendations). Providers will benefit from incorporating information from personal and medical histories that only families possess, resulting in more informed and potentially safer care plans that may be more likely to fit into the family's life at home. SDM can also ensure patient and family "buy-in" and increase the likelihood of compliance with the shared plan.

\section{FAMILY CENTERED DISCHARGES}

Discharge processes often involve multiple redundancies and parallel processes that fail to actively involve families or promote transparency. ${ }^{29}$ Discharge summaries are typically written in medical jargon and intended for the outpatient provider (who may not receive them in a timely fashion), not the family. ${ }^{30-32}$ Separate discharge instructions are often provided to families without sufficient attention to health literacy, contingency planning, or individualization (eg, a generic asthma fact sheet). ${ }^{30}$ Outpatient providers are not always contacted directly about the hospitalization, nor are families always informed when providers are contacted, as Solan et al. describe.

Providers can apply lessons from FCRs to discharge processes, pursuing a similar family-centered, interprofessional approach promoting partnership and transparency. Just as providers engage families during discussions on FCRs, they can engage families in discharge conversations with outpatient providers and nursing colleagues. Indeed, Berry et al. propose a discharge framework that emphasizes involvement of and dialogue between patients, families, and providers as they systematically develop and assess plans for discharge and postdischarge care. ${ }^{33}$ To accomplish this, inpatient providers can copy families on discharge summaries and other correspondence with outpatient providers (eg, through secure emails or open-source notes such as OpenNotes ${ }^{34-36}$ ). Moreover, particularly for complex discharges, inpatient providers can call outpatient providers in the family's presence or invite outpatient providers to join-via telephone or videoconference-day-of-discharge FCRs or discharge huddles. Such efforts require logistical and pragmatic considerations, as well as culture change, but are not insurmountable and may help address many family concerns around peridischarge communication and care. Such efforts may also promote accountability on the part of families and providers alike, thereby ensuring that families are truly engaged as vigilant partners in care.

As one of us (SC) reflected once when considering her experience navigating healthcare as a parent of 2 children with cystic fibrosis, "We have to make it easier for families to be a true part of their children's care. When patients and families are true members of the medical team, care is more informed, more targeted, and more safe for everyone."

Disclosures: Dr. Landrigan has consulted with and holds equity in the I-PASS Patient Safety Institute, a company that seeks to train institutions in best handoff practices and aid in their implementation. Dr. Landrigan is supported in part by the Children's Hospital Association for his work as an Executive Council member of the Pediatric Research in Inpatient Settings (PRIS) network. Dr. Landrigan has also served as a paid consultant to Virgin Pulse to help develop a Sleep and Health Program. In addition, Dr. Landrigan has received monetary awards, honoraria, and travel reimbursement from multiple academic and professional organizations for teaching and consulting on sleep deprivation, physician performance, handoffs, and safety and has served as an expert witness in cases regarding patient safety and sleep deprivation.

\section{References}

1. Sentinel event statistics released for 2014. The Joint Commission. Jt Comm Online. April 2015. http://www.jointcommission.org/assets/1/23/jconline_ April_29_15.pdf. Accessed October 6, 2017.

2. Starmer AJ, Spector ND, Srivastava R, et al. Changes in medical errors after implementation of a handoff program. N Engl J Med. 2014;371(19):18031812. doi:10.1056/NEJMsa1405556.

3. Radhakrishnan K, Jones TL, Weems D, Knight TW, Rice WH. Seamless transitions: achieving patient safety through communication and collaboration. $J$ Patient Saf. 2015. doi:10.1097/PTS.0000000000000168.

4. Haig KM, Sutton S, Whittington J. SBAR: a shared mental model for improving communication between clinicians. Jt Comm J Qual Patient Saf. 2006;32(3):167-175.

5. Lingard L, Regehr G, Orser B, et al. Evaluation of a preoperative checklist and team briefing among surgeons, nurses, and anesthesiologists to reduce failures in communication. Arch Surg. 2008;143(1):12-17; discussion 18. doi:10.1001/archsurg.2007.21.

6. Haynes AB, Weiser TG, Berry WR, et al. A surgical safety checklist to reduce morbidity and mortality in a global population. $N$ Engl J Med. 2009;360(5):491-499. doi:10.1056/NEJMsa0810119.

7. Hibbard JH, Peters E, Slovic P, Tusler M. Can patients be part of the solution? Views on their role in preventing medical errors. Med Care Res Rev. 2005;62(5):601-616. doi:10.1177/1077558705279313.

8. Schwappach DL. Review: engaging patients as vigilant partners in safety: a systematic review. Med Care Res Rev. 2010;67(2):119-148. doi:10.1177/1077558709342254.

9. Solan LG, Beck AF, Shardo SA, et al. Caregiver Perspectives on Communication During Hospitalization at an Academic Pediatric Institution: A Qualitative Study. J Hosp Med. 2018; 13(5):304-310.

10. Mittal VS, Sigrest T, Ottolini MC, et al. Family-centered rounds on pediatric wards: a PRIS network survey of US and Canadian hospitalists. Pediatrics. 2010;126(1):37-43. doi:10.1542/peds.2009-2364.

11. Kuo DZ, Sisterhen LL, Sigrest TE, Biazo JM, Aitken ME, Smith CE. Family experiences and pediatric health services use associated with family-centered rounds. Pediatrics. 2012;130(2):299-305. doi:10.1542/peds.2011-2623. 
12. Mittal $\mathrm{V}$, Krieger $\mathrm{E}$, Lee $B C$, et al. Pediatrics residents' perspectives on family-centered rounds: a qualitative study at 2 children's hospitals. J Grad Med Educ. 2013;5(1):81-87. doi:10.4300/JGME-D-11-00314.1.

13. Ratzan SC, Parker RM. Introduction. In: Selden CR, Zorn M, Ratzan SC, Parke RM, eds. National Library of Medicine current Bibliographies in Medicine: Health Literacy. http://www.nlm.nih.gov/pubs/cbm/hliteracy.html. Accessed October 6, 2017. Vol. NLM. Pub. No. CMB 2000-1. Bethesda, MD: National Institutes of Health, US Department of Health and Human Services; 2000.

14. Baker DW. The Meaning and the Measure of Health Literacy. J Gen Intern Med. 2006;21(8):878-883. doi:10.1111/j.1525-1497.2006.00540.x.

15. Institute of Medicine (US) Committee on Health Literacy. Health Literacy: A Prescription to End Confusion. Nielsen-Bohlman L, Panzer AM, Kindig DA, eds. Washington, DC: National Academies Press; 2004. http://www.ncbi.nlm. nih.gov/books/NBK216032/.

16. Agency for Healthcare Research and Quality. AHRQ Health Literacy Universa Precautions Toolkit. AHRQ Health Literacy Universal Precautions Toolkit. https:// www.ahrq.gov/professionals/quality-patient-safety/quality-resources/tools/literacy-toolkit/index.html. Published May 2017. Accessed October 6, 2017.

17. Bass PF 3rd, Wilson JF, Griffith CH, Barnett DR. Residents' ability to identify patients with poor literacy skills. Acad Med. 2002;77(10):1039-1041.

18. Kelly PA, Haidet P. Physician overestimation of patient literacy: a potential source of health care disparities. Patient Educ Couns. 2007;66(1):119-122 doi:10.1016/j.pec.2006.10.007.

19. Agency for Healthcare Research and Quality. Health Literacy Universal Precautions Toolkit, 2nd Edition. https://www.ahrq.gov/professionals/quality-patient-safety/quality-resources/tools/literacy-toolkit/healthlittoolkit2. html. Published January 30, 2015. Accessed October 6, 2017

20. NHS The Health Literacy Place | Chunk and check. http://www.healthliter acyplace.org.uk/tools-and-techniques/techniques/chunk-and-check/. Accessed September 28, 2017.

21. Health Literacy: Hidden Barriers and Practical Strategies. https://www.ahrq. gov/professionals/quality-patient-safety/quality-resources/tools/literacy-toolkit/tool3a/index.html. Accessed September 28, 2017.

22. Shared Decision Making Fact Sheet. National Learning Consortium. December 2013. https://www.healthit.gov/sites/default/files/nlc_shared_decision_ making_fact_sheet.pdf. Accessed October 3, 2017.

23. Aarthun A, Akerjordet K. Parent participation in decision-making in healthcare services for children: an integrative review. J Nurs Manag. 2014;22(2):177191. doi:10.1111/j.1365-2834.2012.01457.x.

24. Alderson P, Hawthorne J, Killen M. Parents' experiences of sharing neo- natal information and decisions: Consent, cost and risk. Soc Sci Med. 2006;62(6):1319-1329. doi:10.1016/j.socscimed.2005.07.035.

25. Fiks AG, Hughes CC, Gafen A, Guevara JP, Barg FK. Contrasting Parents' and Pediatricians' Perspectives on Shared Decision-Making in ADHD. Pediatrics. 2011;127(1):e188-e196. doi:10.1542/peds.2010-1510.

26. Stiggelbout AM, Van der Weijden T, De Wit MP, et al. Shared decision making: really putting patients at the centre of healthcare. BMJ. 2012;344:e256. doi:10.1136/bmj.e256.

27. Kon AA, Davidson JE, Morrison W, et al. Shared Decision Making in ICUs: An American College of Critical Care Medicine and American Thoracic Society Policy Statement., Shared Decision Making in Intensive Care Units: An American College of Critical Care Medicine and American Thoracic Society Policy Statement. Crit Care Med. 2016;44(1):188-201. doi:10.1097/ CCM.0000000000001396.

28. Chorney J, Haworth R, Graham ME, Ritchie K, Curran JA, Hong P. Understanding Shared Decision Making in Pediatric Otolaryngology. Otolaryngol Head Neck Surg. 2015;152(5):941-947. doi:10.1177/0194599815574998.

29. Wibe T, Ekstedt M, Hellesø R. Information practices of health care professionals related to patient discharge from hospital. Inform Health Soc Care. 2015;40(3):198-209. doi:10.3109/17538157.2013.879150

30. Kripalani S, Jackson AT, Schnipper JL, Coleman EA. Promoting effective transitions of care at hospital discharge: a review of key issues for hospitalists. J Hosp Med. 2007;2(5):314-323. doi:10.1002/jhm.228.

31. van Walraven $C$, Seth $R$, Laupacis $A$. Dissemination of discharge summaries. Not reaching follow-up physicians. Can Fam Physician. 2002;48:737-742.

32. Leyenaar JK, Bergert L, Mallory LA, et al. Pediatric primary care providers' perspectives regarding hospital discharge communication: a mixed methods analysis. Acad Pediatr. 2015;15(1):61-68. doi:10.1016/j.acap.2014.07.004.

33. Berry JG, Blaine K, Rogers J, et al. A framework of pediatric hospital discharge care informed by legislation, research, and practice. JAMA Pediatr. 2014;168(10):955-962; quiz 965-966. doi:10.1001/jamapediatrics.2014.891.

34. Bell SK, Gerard M, Fossa A, et al. A patient feedback reporting tool for OpenNotes: implications for patient-clinician safety and quality partnerships. BMJ Qual Saf. 2017;26(4):312-322. doi:10.1136/bmjqs-2016-006020.

35. Bell SK, Mejilla R, Anselmo M, et al. When doctors share visit notes with patients: a study of patient and doctor perceptions of documentation errors, safety opportunities and the patient-doctor relationship. BMJ Qual Saf. 2017;26(4):262-270. doi:10.1136/bmjas-2015-004697.

36. A Strong Case for Sharing. Open Notes. https://www.opennotes.org/casefor-opennotes/. Accessed September 19, 2017. 